\title{
Consensus on pre-operative total knee replacement education and prehabilitation recommendations: a UK-based modified Delphi study
}

\author{
Anna M. Anderson ${ }^{1,2^{*}}$ D, Christine Comer ${ }^{1,3}$, Toby O. Smith ${ }^{4,5}$, Benjamin T. Drew ${ }^{1}$, Hemant Pandit ${ }^{1,2}$,
} Deborah Antcliffo, ${ }^{6}$, Anthony C. Redmond ${ }^{1,2}$ and Gretl A. McHugh ${ }^{6}$

\begin{abstract}
Background: Over 90,000 total knee replacement (TKR) procedures are performed annually in the United Kingdom (UK). Patients awaiting TKR face long delays whilst enduring severe pain and functional limitations. Almost 20\% of patients who undergo TKR are not satisfied post-operatively. Optimising pre-operative TKR education and prehabilitation could help improve patient outcomes pre- and post-operatively; however, current pre-operative TKR care varies widely. Definitive evidence on the optimal content and delivery of pre-operative TKR care is lacking. This study aimed to develop evidence- and consensus-based recommendations on pre-operative TKR education and prehabilitation.
\end{abstract}

Methods: A UK-based, three-round, online modified Delphi study was conducted with a 60-member expert panel. All panellists had experience of TKR services as patients $(n=30)$ or professionals $(n=30)$. Round 1 included initial recommendations developed from a mixed methods rapid review. Panellists rated the importance of each item on a five-point Likert scale. Panellists could also suggest additional items in Round 1. Rounds 2 and 3 included all items from Round 1, new items suggested in Round 1 and charts summarising panellists' importance ratings from the preceding round. Free-text responses were analysed using content analysis. Quantitative data were analysed descriptively. All items rated as 'Important' or 'Very important' by at least 70\% of all respondents in Round 3 were included in the final set of recommendations.

Results: Fifty-five panellists (92\%) (patients $n=26$; professionals $n=29$ ) completed Round 3. Eighty-six recommendation items were included in Round 1. Fifteen new items were added in Round 2. Rounds 2 and 3 therefore included 101 items. Seventy-seven of these reached consensus in Round 3. Six items reached consensus amongst patient or professional panellists only in Round 3. The final set of recommendations comprises 34 education topics, 18 education delivery approaches, 10 exercise types, 13 exercise delivery approaches and two other treatments.

(Continued on next page)

\footnotetext{
* Correspondence: A.Anderson@leeds.ac.uk

'Leeds Institute of Rheumatic \& Musculoskeletal Medicine, University of Leeds, Leeds, UK

${ }^{2} \mathrm{NIHR}$ Leeds Biomedical Research Centre, Leeds, UK

Full list of author information is available at the end of the article
}

(c) The Author(s). 2021 Open Access This article is licensed under a Creative Commons Attribution 4.0 International License, which permits use, sharing, adaptation, distribution and reproduction in any medium or format, as long as you give appropriate credit to the original author(s) and the source, provide a link to the Creative Commons licence, and indicate if changes were made. The images or other third party material in this article are included in the article's Creative Commons licence, unless indicated otherwise in a credit line to the material. If material is not included in the article's Creative Commons licence and your intended use is not permitted by statutory regulation or exceeds the permitted use, you will need to obtain permission directly from the copyright holder. To view a copy of this licence, visit http://creativecommons.org/licenses/by/4.0/. The Creative Commons Public Domain Dedication waiver (http://creativecommons.org/publicdomain/zero/1.0/) applies to the data made available in this article, unless otherwise stated in a credit line to the data. 
(Continued from previous page)

Conclusions: This modified Delphi study developed a comprehensive set of recommendations that represent a useful resource for guiding decision-making on the content and delivery of pre-operative TKR education and prehabilitation. The recommendations will need to be interpreted and reviewed periodically in light of emerging evidence.

Keywords: Total knee replacement, Total knee arthroplasty, Pre-operative care, Education, Prehabilitation, Exercise, Delphi study

\section{Background}

The demand for total knee replacement (TKR) surgery is rising $[1,2]$, with over 90,000 TKR procedures already being performed annually in the United Kingdom (UK) [3, 4]. Patients awaiting TKR often experience severe pain, functional limitations and psychological distress [5-7]. Almost 20\% of patients are not satisfied following TKR surgery $[8,9]$. This is related to multiple factors, of which failure to meet preoperative expectations is key $[8,10]$. Even amongst patients who are satisfied with their TKR, the prevalence of residual symptoms such as swelling, stiffness and functional limitations is high [11-13].

Optimising pre-operative TKR care is an important strategy for addressing the above issues [14-16]. For example, pre-operative TKR education helps set realistic expectations $[14,17]$ and may reduce pre-operative anxiety [14] and length of hospital stay [18]. Systematic reviews suggest that pre-operative TKR exercise also shortens length of hospital stay and improves postoperative outcomes $[16,19]$. Pre-operative exercise is a key component of prehabilitation programmes, which are designed to facilitate patients' post-operative recovery by optimising their pre-operative health and wellbeing [20,21]. A multimodal approach to prehabilitation is however advocated; therefore, prehabilitation programmes may also include other interventions such as smoking cessation and psychological support [20,21].

Despite the potential benefits of pre-operative TKR education and prehabilitation, current UK pre-operative TKR services vary widely [22-24]. For example, not all hospitals provide a formal pre-operative TKR education and prehabilitation programme [22]. Amongst those that do, there is variation in the programme content and whether it is provided in a group or one-to-one format [22]. A recently published UK National Institute for Health and Care Excellence guideline states that patients awaiting TKR surgery should receive pre-operative information and advice on prehabilitation [22]. This guideline lacks details about the content and delivery of preoperative TKR care however and, given it identified uncertainties regarding how best to deliver pre-operative information and relied predominantly on low quality underpowered prehabilitation studies, the need for further research in this area is highlighted [22]. This need is pressing because the UK 18-week referral to treatment standard was frequently breached for TKR surgery in 2019 [25] and the COVID-19 (SARS-CoV-2) pandemic is increasing TKR waiting times further [26]. Therefore, patients listed for TKR surgery are currently likely to require prehabilitation for a prolonged period. The COVID-19 pandemic is also catalysing health service redesign $[27,28]$, presenting an opportune time for research to inform service provision.

The aim of the present study was therefore to develop evidence- and consensus-based recommendations on the content and delivery of pre-operative TKR education and prehabilitation. Previous consensus-based studies have addressed TKR care [29-33]. None of these studies focused exclusively on pre-operative TKR education and prehabilitation however, and their findings cannot be directly applied to the UK context [34]. Additionally, patient representation on their expert panels was minimal or absent [29-33], despite the key role of patients in guideline development [35]. The present study sought to overcome these issues by employing a UK-based expert panel with equal numbers of patient and professional panellists.

The purpose of the recommendations is to help guide clinical practice until more robust evidence on preoperative TKR education and prehabilitation becomes available. This study is the first phase of a mixed methods project aimed at developing a pre-operative TKR education and prehabilitation digital intervention. Correspondingly, the recommendations will also inform the digital intervention development.

\section{Methods}

This was a three-round online modified Delphi study (Fig. 1). The study is reported in line with recommendations for the Conducting and REporting of DElphi Studies (CREDES) [36] and proposed Delphi study reporting quality indicators [37]. Ethical approval was obtained from the London - Riverside Research Ethics Committee (Reference number: 19/LO/0813). A Project Advisory Group, involving four project team members, two patient representatives, an independent chair and a key collaborator, oversaw the study. This group met twice 


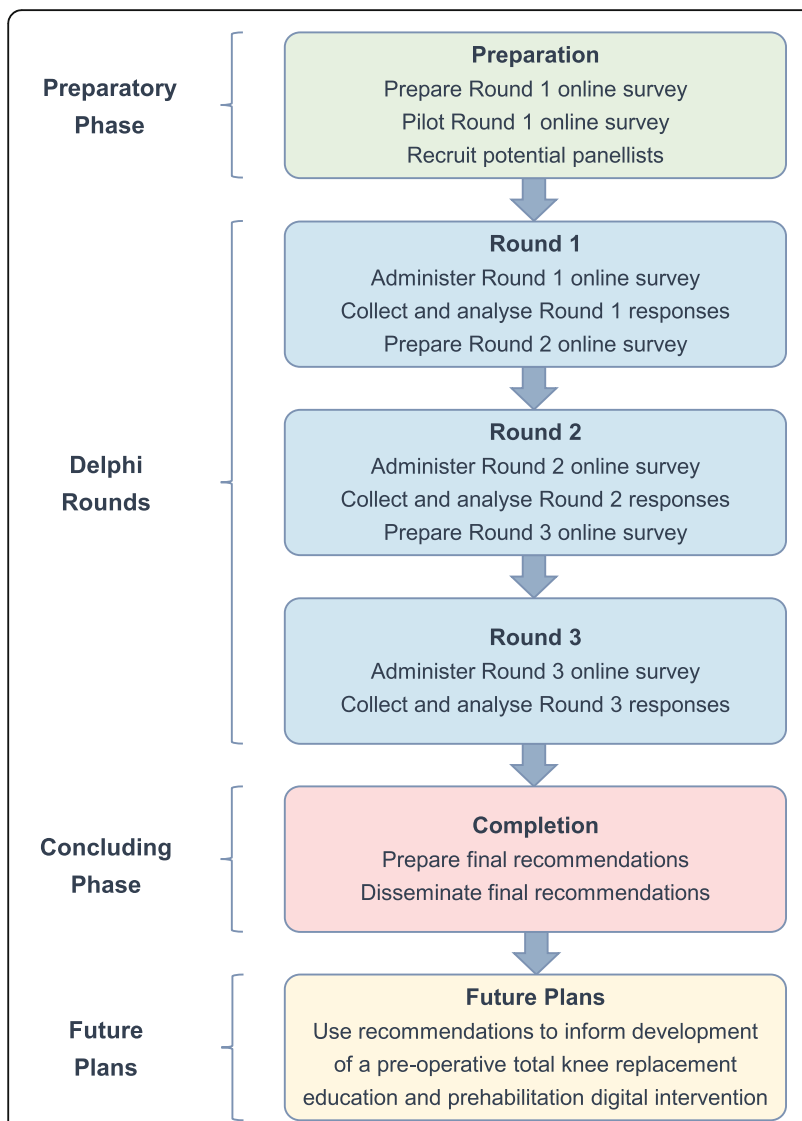

Fig. 1 Flow chart of the Delphi process. Flow chart stages based on recommendations from Jünger et al. (2017) [36]

during the study, approximately 6 months apart. The first meeting was held prior to data collection. The second meeting was held after completion of data collection.

A modified Delphi technique was employed, in which the initial round was developed from existing evidence [38]. This approach was chosen to minimise the burden on panellists $[39,40]$ and optimise the quality of the recommendations [41].

\section{Expert panel}

There are no established guidelines on the optimal Delphi study panel size [42]. Therefore, a target of 24 to 70 panellists was set to ensure key stakeholders were sufficiently represented and the panel remained manageable. Panellists were selected using stratified purposive sampling of a minimum number of patients and professionals from key groups, availability sampling of patients and professionals and snowball sampling of professionals [43-45]. It was decided a priori to include a minimum of six patients listed for TKR surgery, six patients who had undergone TKR surgery and two of the following professionals: orthopaedic surgeons, advanced arthroplasty practitioners, nurses, physiotherapists, occupational therapists and clinical commissioners (Additional File 1).

Patients were recruited via social media and Leeds Teaching Hospitals NHS Trust orthopaedic clinics. Although patients were not actively encouraged to share the study details, patients who heard about the study via word-of-mouth were included. Professionals were recruited from all four UK nations via social media, professional networks and encouraging professionals to share the study details with other professionals.

Adults able to communicate in English and use/access the Internet and email were eligible for inclusion if they had experience of TKR services through any of the following:

- Patient who is listed for TKR surgery

- Patient who has undergone TKR surgery within the past 2 years

- Health professional with experience of working with patients undergoing TKR surgery in the NHS

- Clinical commissioner with experience of commissioning orthopaedic services

\section{Data collection}

Data were collected between 13th December 2019 and 19th March 2020. It was decided a priori to include three rounds to increase convergence whilst minimising participant attrition [38, 42, 46] (Fig. 1). All three surveys were hosted using the Online surveys tool [47] and administered via email. A consent statement was included on each survey's introductory page. Panellists were required to complete the consent statement prior to completing the remainder of the survey. Reminders were provided via email and/or telephone to help maximise response rates [38]. All individuals who completed Round 1 were subsequently emailed links to Rounds 2 and 3.

\section{Round 1}

Round 1 included an initial set of pre-operative TKR education and prehabilitation recommendations (Additional File 2). The initial recommendations were based on a mixed methods rapid review (PROSPERO registration number: CRD42019143248, to be reported in full elsewhere) and covered five sections:

1. Pre-operative TKR education topics (29 items)

2. Pre-operative TKR education delivery (22 items)

3. Pre-operative TKR exercise types (14 items)

4. Pre-operative TKR exercise programme delivery (16 items)

5. Other pre-operative TKR treatments (5 items) 
Where appropriate, items included a 'More info' option that panellists could click on to read an explanation of that item. Panellists were asked to rate each recommendation item on a five-point Likert scale from 'Not at all important' to 'Very important'. Free-text options were included at the end of each recommendation section to allow panellists to suggest additional items.

Round 1 also included questions on panellists' characteristics. Separate sets of questions were included for patient panellists (focused on their socio-demographic and clinical characteristics) and professional panellists (focused on their workplace, role and experience).

Prior to full circulation, Round 1 was pilot tested by seven study team members, three physiotherapists, one nurse and three patient representatives. This led to minor wording/structural changes for clarity; amendments to five recommendation items, predominantly to make the items more applicable to clinical practice; inclusion of five new recommendation items, which the pilot testers perceived were important to consider; and inclusion of six additional 'More info' options (five of which explained health professional teams' roles) to assist any panellists who were unfamiliar with the terms used.

No individuals who pilot tested Round 1 joined the main expert panel. Round 1 took panellists a median of 20 min $18 \mathrm{~s}$ online time to complete.

\section{Round 2}

Round 2 included all the recommendation items from Round 1 to ensure all items had equal opportunity of reaching as high a level of consensus as possible [38]. This approach was chosen to enable prioritisation of the items based panellists' responses in the final round.

Each item from Round 1 was accompanied by three charts showing panellists' importance ratings for that item in Round 1 (Fig. 2). Providing panellists with a summary of the results of the preceding round is an established approach for encouraging panellists to reconsider their initial judgement and hence facilitate the development of consensus [42, 48].

Round 2 also included additional recommendation items generated from the Round 1 free-text responses. As in Round 1, panellists were asked to rate the importance of each item using a five-point Likert scale. No free-text options were included in Round 2 to minimise panellist and researcher burden. Round 2 took panellists a median of $17 \mathrm{~min} 53 \mathrm{~s}$ online time to complete.

\section{Round 3}

Round 3 followed the same format as Round 2, with inclusion of all the Round 2 items accompanied by three charts summarising panellists' Round 2 importance ratings. As in the preceding rounds, panellists were asked to rate the importance of each item using a five-point Likert scale. Round 3 took panellists a median of $16 \mathrm{~min}$ $31 \mathrm{~s}$ online time to complete.

\section{Data analysis \\ Free-text responses}

The Round 1 free-text responses were analysed using directed content analysis $[49,50]$. This involved creating a 'formative categorisation matrix' based on the Round 1 survey (Additional File 3). Each recommendation section was considered a main category. Each recommendation item was considered a potential subcategory. The free-text responses were inductively coded. Where possible, codes were included within the pre-specified sub-categories. Codes that did not fit within the pre-specified sub-categories were included in new, inductively generated sub-categories. The sub-categories were then grouped into generic categories. The generic categories were reviewed to determine whether any new main categories were required. The content analysis was undertaken by one study team member (AMA). All aspects of the analysis were verified by at least one additional study team member (GAM, CC).

All inductively generated sub-categories relating to a pre-operative TKR intervention component or delivery approach were considered potential new items for inclusion in Round 2. It was specified a priori in the protocol that all potential new items would be included, unless that would result in Round 2 taking significantly longer than $30 \mathrm{~min}$ to complete, in which case only new items suggested by more than a threshold percentage of panellists would be included. This approach was chosen to help ensure that potentially important items were not omitted from consideration, whilst also ensuring the time burden for panellists remained manageable.

\section{Quantitative data}

The panellist characteristics and importance ratings were analysed descriptively using Microsoft Excel 2016 and IBM SPSS Statistics 23. There are no established guidelines on how to define consensus in Delphi studies [37], however percent agreement is frequently used [37], and $70 \%$ is a commonly specified threshold [51-53]. Consensus was therefore provisionally defined as at least $70 \%$ of respondents rating an item as 'Important' or 'Very important'. Specifying a consensus threshold a priori may lead to important items being omitted due to narrowly missing the arbitrary threshold [37]. To account for this, the 70\% threshold was reviewed following completion of 


\section{Recommendation 1}

At a minimum, pre-operative TKR education should include the following topics:

\section{Background information}

This part of the survey uses a table of questions, view as separate questions instead?

\subsection{Anatomy of the knee joint}
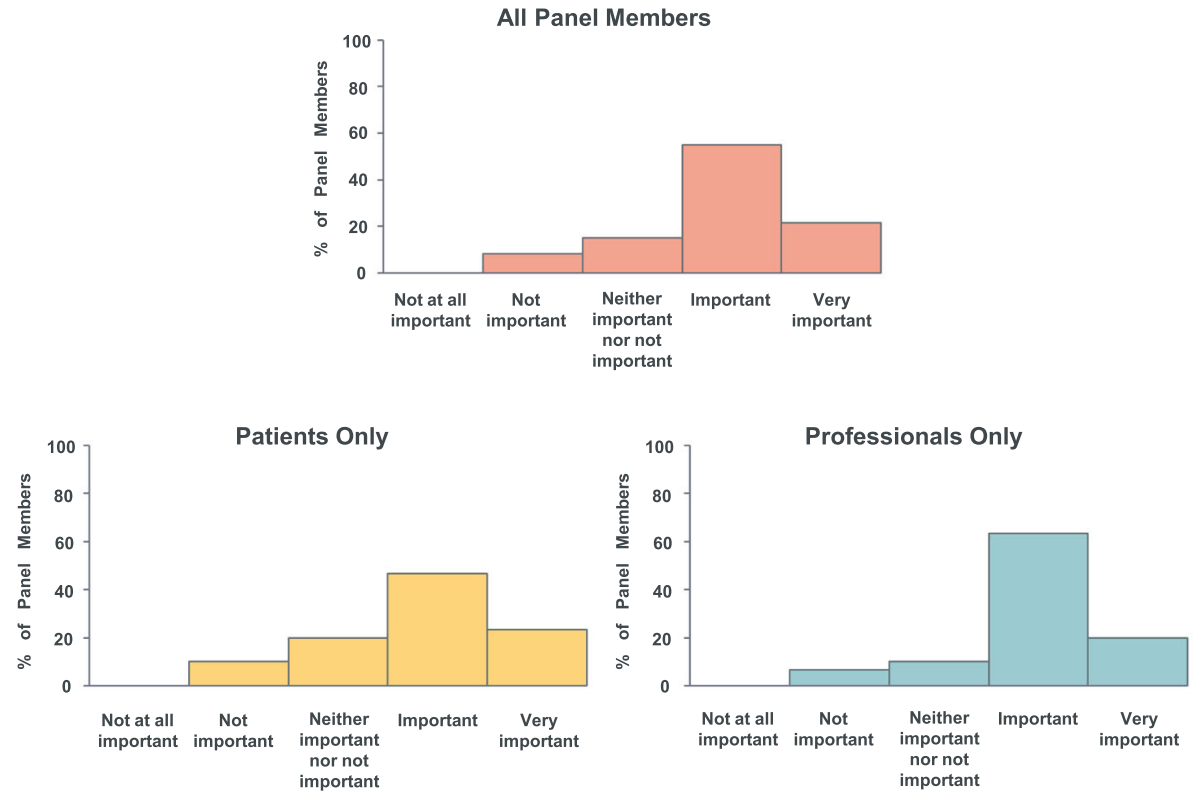

More info

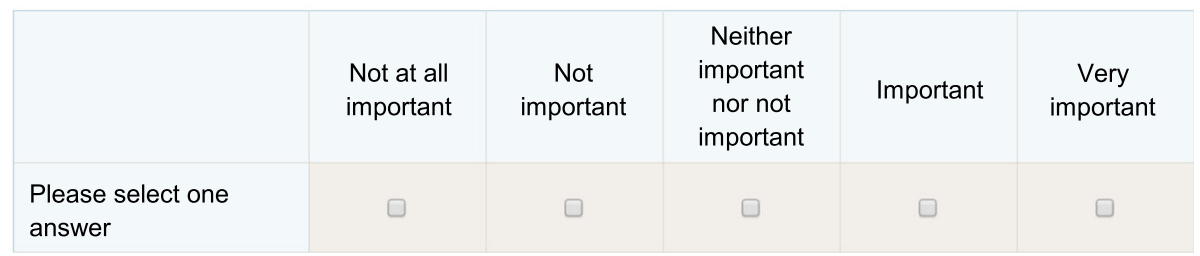

Fig. 2 Round 2 recommendation item example

Round 3 by the Project Advisory Group, who felt no amendments were required.

Responses were analysed for all panellists considered together and for patient and professional panellists separately. All items that reached consensus in Round 3 amongst all respondents considered together were included in the final set of recommendations.

To facilitate use of the recommendations in clinical practice and help guide future research, a prioritised list of recommendations was developed by grouping the recommendation items into three categories:

- Very important recommendations: Items rated as 'Very important' by at least 70\% of all respondents in Round 3, ranked according to the percentage of 'Very important' ratings.
- Important recommendations: Items rated as 'Important or 'Very important' by at least $70 \%$ of all respondents in Round 3 (excluding those categorised as 'Very important'), ranked according to the percentage of 'Important' or 'Very important' ratings.

- Excluded recommendations: Items rated as 'Important' or 'Very important' by less than $70 \%$ of all respondents in Round 3, ranked according to the percentage of 'Important' or 'Very important' ratings.

\section{Results}

Expert panel

One hundred and twenty-one individuals were screened, of whom 95 met the eligibility criteria. Twenty-two of these individuals were excluded due to lack of response 
following the initial contact (one patient, eight professionals) or because a sufficient number of relevant professional panellists had already been recruited (13 professionals). The remaining 73 individuals were emailed the link to Round 1. Sixty individuals (30 patients, 30 professionals) completed Round 1 and formed the expert panel (Fig. 3, reasons for exclusions at each stage available in Additional File 4).

Rounds 2 and 3 were completed by 95 and 92\% of panellists respectively. The professional panellist who did not complete Round 2 indicated this was due to being on leave. No other non-respondents provided reasons for non-completion. Tables 1 and 2 provide the patient and professional characteristics respectively.

\section{Free-text responses}

Thirty-eight panellists (15 patients, 23 professionals) provided at least one free-text response, resulting in an extensive final categorisation matrix (Additional File 5). The majority of comments fitted within the pre-specified sub-categories. However, 34 new sub-categories were inductively generated. Seven new sub-categories related to TKR care in general, rather than specific intervention components and delivery approaches. These were grouped into a new main category, 'Planning and prioritising TKR care' (Additional File 6), and were not included in Round 2.

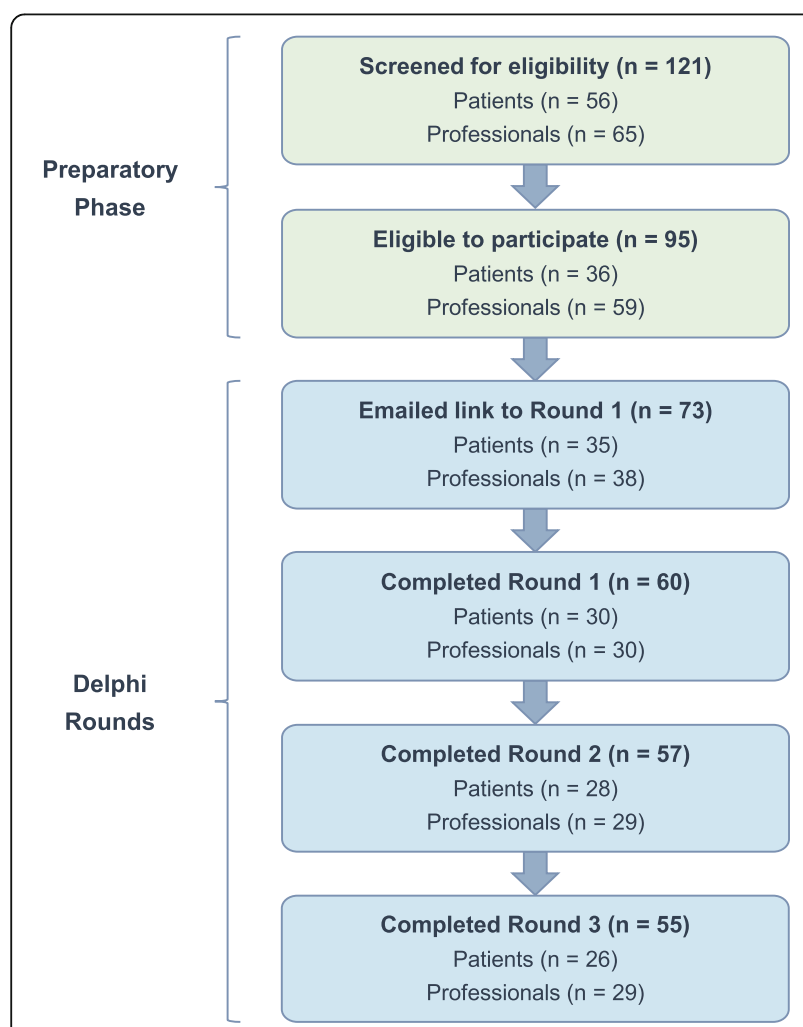

Fig. 3 Expert panel flow chart
Table 1 Patient panellist characteristics

Number of panellists

(\%) $(n=30)$

\begin{tabular}{ll}
\hline Living location & $1(3 \%)$ \\
Scotland & $3(10 \%)$ \\
North East & $5(17 \%)$ \\
North West & $7(23 \%)$ \\
Yorkshire and the Humber & $1(3 \%)$ \\
East Midlands & $3(10 \%)$ \\
West Midlands & $1(3 \%)$ \\
South West & $4(13 \%)$ \\
South East & $5(17 \%)$ \\
East of England & \\
Age & $4(13 \%)$ \\
$40-49$ years & $9(30 \%)$ \\
$50-59$ years & $11(37 \%)$ \\
$60-69$ years & $6(20 \%)$ \\
$70-79$ years &
\end{tabular}

\section{Gender}

Male

$10(33 \%)$

Female

$20(67 \%)$

Ethnicity

White British

$30(100 \%)$

Highest educational qualification

$\begin{array}{ll}\text { None } & 4(13 \%) \\ \text { GCSE / O Level (or equivalent) } & 5(17 \%) \\ \text { A Level (or equivalent) } & 2(7 \%) \\ \text { Vocational qualification (or equivalent) } & 10(33 \%) \\ \text { Undergraduate degree } & 3(10 \%) \\ \text { Postgraduate degree } & 6(20 \%)\end{array}$

Current employment status ${ }^{a}$

$\begin{array}{ll}\text { Employed full-time } & 9(30 \%) \\ \text { Employed part-time } & 7(23 \%) \\ \text { Retired } & 13(43 \%) \\ \text { Sick leave } & 2(7 \%) \\ \text { Medically disabled } & 2(7 \%)\end{array}$

Experience of TKR surgery ${ }^{a}$

Listed for TKR surgery 11 (37\%)

Previously undergone TKR surgery 23 (77\%)

TKR Total knee replacement

a Panellists could select more than one option

Across the five pre-specified main categories, 27 new sub-categories were inductively generated. Piloting of Round 2 by study team members suggested that inclusion of all 27 new items could result in the survey taking significantly longer than $30 \mathrm{~min}$ to complete. Therefore, 
Table 2 Professional panellist characteristics

\begin{tabular}{|c|c|}
\hline & $\begin{array}{l}\text { Number of panellists } \\
(\%)(n=30)\end{array}$ \\
\hline \multicolumn{2}{|l|}{ Workplace location } \\
\hline Scotland & $2(7 \%)$ \\
\hline Northern Ireland & $4(13 \%)$ \\
\hline Wales & $2(7 \%)$ \\
\hline North West & $5(17 \%)$ \\
\hline Yorkshire and the Humber & $9(30 \%)$ \\
\hline South West & $3(10 \%)$ \\
\hline South East & $1(3 \%)$ \\
\hline London & $4(13 \%)$ \\
\hline \multicolumn{2}{|l|}{ Current professional role ${ }^{a}$} \\
\hline Orthopaedic surgeon & $5(17 \%)$ \\
\hline Advanced arthroplasty practitioner & $2(7 \%)$ \\
\hline Nurse & $2(7 \%)$ \\
\hline Physiotherapist & $12(40 \%)$ \\
\hline Occupational therapist & $4(13 \%)$ \\
\hline Rehabilitation assistant & $3(10 \%)$ \\
\hline Psychotherapist & $1(3 \%)$ \\
\hline Clinical commissioner & $3(10 \%)$ \\
\hline Manager & $2(7 \%)$ \\
\hline Researcher & $2(7 \%)$ \\
\hline \multicolumn{2}{|l|}{ Years' experience as a health professional } \\
\hline $0-9$ & $5(17 \%)$ \\
\hline $10-19$ & $11(37 \%)$ \\
\hline $20-29$ & $9(30 \%)$ \\
\hline $30-49$ & $5(17 \%)$ \\
\hline \multicolumn{2}{|l|}{ Workplace setting $^{a}$} \\
\hline NHS teaching hospital & $18(60 \%)$ \\
\hline NHS district/general hospital & $7(23 \%)$ \\
\hline Private Hospital or other private location(s) & $5(17 \%)$ \\
\hline Commissioning organisation & $3(10 \%)$ \\
\hline Increasing Access to Psychological Therapies & $1(3 \%)$ \\
\hline
\end{tabular}

Currently provide clinical care to patients who are listed for or have undergone TKR surgery

$\begin{array}{ll}\text { Yes } & 27(90 \%) \\ \text { No } & 3(10 \%)\end{array}$

Phases of the TKR pathway currently work in $(n=27)^{a, b}$

$\begin{array}{ll}\text { Pre-operative phase } & 20(74 \%) \\ \text { Acute phase } & 20(74 \%) \\ \text { Post-operative phase } & 19(70 \%)\end{array}$

Table 2 Professional panellist characteristics (Continued)

Number of panellists

(\%) $(n=30)$

Number of patients who are listed for or have undergone TKR surgery seen during previous week $(n=27)^{\mathrm{b}}$

0

$1-2$

$3-5$

$6-10$

$>10$

TKR Total knee replacement

a Panellists could select more than one option

${ }^{b}$ Only includes panellists who indicated they currently provide clinical care to patients who are listed for/have undergone total knee replacement surgery

in line with protocol, only new items suggested by at least two panellists (3\% of all panellists) were included (see Methods, Data analysis, Free-text responses for further details). This resulted in an additional 15 new items being included in Round 2 (Table 3, Additional File 7).

\section{Importance ratings overview}

Based on the rapid review, eighty-six recommendation items were included in Round 1. Fifteen new items were added in Round 2. Seventy-seven of the resulting 101 items were included in the final set of recommendations (Tables 3, 4, 5, 6, 7, 8, Additional File 8). The importance ratings of patient and professional panellists were largely similar (Additional File 9). Overall however, patient panellists provided lower importance ratings than professional panellists, especially during Round 1. The number of items that reached consensus amongst patient but not professional panellists was three, five and one in Rounds 1,2 and 3 respectively. The number of items that reached consensus amongst professional but not patient panellists was 13, six and five in Rounds 1,2 and 3 respectively. Sixteen recommendation items were prioritised as 'Very important' and 61 were prioritised as 'Important' (Additional File 10).

\section{Pre-operative TKR education topics}

Twenty-nine education topic items were included in Round 1. Six were added in Round 2. Thirty-four of the resulting 35 items were included in the final set of recommendations (Table 4). All 34 included items reached consensus amongst patient and professional panellists in Round 3 (Additional File 9). Twelve of the included education topic items were prioritised as 'Very important' and 22 were prioritised as 'Important' (Table 4, Additional File 10). 
Table 3 Recommendation items summary

\begin{tabular}{|c|c|c|c|c|c|c|}
\hline & \multicolumn{6}{|c|}{ Number of recommendation items } \\
\hline & \multicolumn{2}{|c|}{ Round 1} & \multicolumn{2}{|c|}{ Round 2} & \multicolumn{2}{|c|}{ Round 3} \\
\hline & Total $^{\mathrm{a}}$ & Reached consensus $^{\mathbf{b}}$ & Total $^{\mathrm{a}}$ & Reached consensus $^{\mathbf{b}}$ & Total $^{a}$ & Reached consensus ${ }^{b}$ \\
\hline Pre-operative TKR education topics & 29 & 28 & 35 & 34 & 35 & 34 \\
\hline Pre-operative TKR education delivery & 22 & 14 & 25 & 17 & 25 & 18 \\
\hline Pre-operative TKR exercise types & 14 & 7 & 17 & 8 & 17 & 10 \\
\hline Pre-operative TKR exercise delivery & 16 & 8 & 19 & 11 & 19 & 13 \\
\hline Other pre-operative TKR treatments & 5 & 0 & 5 & 1 & 5 & 2 \\
\hline All recommendation items & 86 & 57 & 101 & 71 & 101 & 77 \\
\hline
\end{tabular}

TKR Total knee replacement

a Total number of recommendation items included in the round

${ }^{b}$ Number of recommendation items in the round that reached consensus. Consensus was defined as at least $70 \%$ of respondents rating an item as 'Important' or 'Very important'

\section{Pre-operative TKR education delivery}

Twenty-two education delivery items were included in Round 1. Three were added in Round 2. Eighteen of the resulting 25 items were included in the final set of recommendations (Table 5). All 18 included items reached consensus amongst patient and professional panellists in Round 3 (Additional File 9). Informed by members of the physiotherapy team (Item 2.2.3) and provide an opportunity for questions to be addressed (Item 2.8) were prioritised as 'Very important'. The remaining 16 included education delivery items were prioritised as 'Important' (Table 5, Additional File 10).

\section{Pre-operative TKR exercise types}

Fourteen exercise type items were included in Round 1. Three were added in Round 2. Ten of the resulting 17 items were included in the final set of recommendations (Table 6). Cardiovascular exercises (Item 3.11) and core control exercises (Item 3.12) reached consensus amongst professional but not patient panellists in Round 3 (Additional File 9). Additionally, arm strengthening exercises (Item 3.2) reached consensus amongst patient but not professional panellists in Round 3. Arm strengthening exercises did not reach consensus amongst all panellists considered together and therefore was excluded from the final recommendations. Leg strengthening exercises (Item 3.1) and leg flexibility exercises (Item 3.3) were prioritised as 'Very important'. The remaining eight included exercise type items were prioritised as 'Important' (Table 6, Additional File 10).

\section{Pre-operative TKR exercise programme delivery}

Sixteen exercise programme delivery items were included in Round 1. Three were added in Round 2. Thirteen of the resulting 19 items were included in the final set of recommendations (Table 7). An opportunity for peer support (Item 4.11) reached consensus amongst professional but not patient panellists in Round 3
(Additional File 9). All 13 included exercise programme delivery items were prioritised as 'Important' (Table 7, Additional File 10).

\section{Other pre-operative TKR treatments}

Five other pre-operative TKR treatment items were included in Round 1 and none were added in Round 2. Referral of patients with a body mass index (BMI) of $27 \mathrm{~kg} / \mathrm{m}^{2}$ or over to a weight management programme (Item 5.1) and offering cognitive behavioural (CBT)based therapy to patients who have been formally diagnosed with anxiety or depression (Item 5.2) were included in the final recommendations (Table 8). Both of these items reached consensus amongst professional but not patient panellists in Round 3 (Additional File 9) and were prioritised as 'Important' (Table 8, Additional File 10).

\section{Discussion}

This UK-based modified Delphi study developed a comprehensive set of recommendations on the content and delivery of pre-operative TKR education and prehabilitation. Of the 77 items included in the final recommendations, the largest proportion are education topics (Tables 3-4). Smaller proportions are education delivery approaches, exercise delivery approaches and exercise types (Tables 5, 6, 7). A minority of the items are other treatments not focused on education or exercise (Table 8). Correspondingly, the level of agreement between panellists was greater for the education topics section than for any other section, with 12 education topics receiving 'Important' or 'Very important' ratings from $100 \%$ of panellists in the final round (Table 4).

The importance ratings of patient and professional panellists were broadly similar. However, arm strengthening exercises reached consensus amongst patient but not professional panellists only in the final round 
Table 4 Pre-operative total knee replacement education topics: Importance ratings summary

\begin{tabular}{|c|c|c|c|}
\hline \multirow[t]{2}{*}{ Pre-operative total knee replacement education topic item ${ }^{a}$} & \multicolumn{3}{|c|}{$\%$ Important or Very Important rating } \\
\hline & Round $1(n=60)$ & Round $2(n=57)$ & Round $3(n=55)$ \\
\hline 1.1 Anatomy of the knee joint & 77 & 91 & 95 \\
\hline 1.2 Health conditions that may contribute to needing TKR surgery & 77 & 95 & 91 \\
\hline 1.3 Alternative treatment options to TKR surgery & 82 & 91 & 87 \\
\hline 1.4 Purpose of pre-operative rehabilitation & 98 & 98 & 98 \\
\hline 1.5 Patient involvement in their own management & 98 & 100 & 98 \\
\hline 1.6 Goal setting & 88 & 93 & 96 \\
\hline 1.7 Using heat and cold & 87 & 88 & 85 \\
\hline 1.8 Obtaining and using walking aids and other equipment & 95 & 96 & 95 \\
\hline 1.9 Making home preparations & 98 & 98 & 100 \\
\hline 1.10 Arranging social support & 88 & 95 & 96 \\
\hline 1.11 Arranging transport to and from the hospital & 82 & 91 & 98 \\
\hline 1.12 What to expect during the hospital stay & 98 & 100 & 100 \\
\hline 1.13 What a TKR surgical procedure involves & 92 & 89 & 93 \\
\hline 1.14 Risks of TKR surgery and how to minimise them & 97 & 100 & 100 \\
\hline $\begin{array}{l}1.15 \text { Common issues that may occur following TKR surgery } \\
\text { which do not need to cause alarm }\end{array}$ & 93 & 98 & 100 \\
\hline 1.16 Pain expectations & 97 & 100 & 100 \\
\hline 1.17 What to expect following discharge & 95 & 98 & 100 \\
\hline 1.18 Recovery expectations & 98 & 98 & 98 \\
\hline 1.19 Pain management & 100 & 100 & 100 \\
\hline 1.20 Rehabilitation following TKR surgery & 100 & 100 & 100 \\
\hline 1.21 Complementary and alternative therapies & 28 & 21 & 27 \\
\hline 1.22 Returning to daily activities & 93 & 100 & 98 \\
\hline 1.23 Returning to driving and other types of travel & 95 & 96 & 98 \\
\hline 1.24 Returning to sports and leisure activities & 90 & 89 & 96 \\
\hline 1.25 Returning to work & 88 & 95 & 95 \\
\hline 1.26 Physical activity & 95 & 98 & 100 \\
\hline 1.27 Weight management & 90 & 98 & 100 \\
\hline 1.28 Stopping smoking & 80 & 84 & 85 \\
\hline 1.29 Avoiding alcohol misuse & 73 & 82 & 87 \\
\hline 1.30 Optimising management of diabetes & N/A & 77 & 82 \\
\hline 1.31 Education for other people, such as carers & N/A & 82 & 91 \\
\hline 1.32 Swelling & N/A & 98 & 100 \\
\hline 1.33 Organising help if complications occur & N/A & 100 & 100 \\
\hline 1.34 Returning to a normal walking pattern & N/A & 93 & 98 \\
\hline 1.35 Emotional well-being & N/A & 89 & 93 \\
\hline
\end{tabular}

N/A Not applicable because the item was not included in Round 1

TKR Total knee replacement

${ }^{a}$ Consensus was defined as at least $70 \%$ of respondents rating an item as 'Important' or 'Very important'. The item in italics did not reach consensus in Round 3 and hence was excluded from the final list of recommendations. Items in bold were prioritised as 'Very important'. Items in plain text were prioritised as 'Important'

(Item 3.2; Additional File 9). Conversely, cardiovascular exercises, core control exercises, an opportunity for peer support, referral to a weight management programme and CBT-based therapy all reached consensus amongst professional but not patient panellists in the final round (Items 3.11, 3.12, 4.11, 5.1, 5.2; Additional File 9). Reasons for this could not be explored in the current study. Qualitative research 
Table 5 Pre-operative total knee replacement education delivery: Importance ratings summary

\begin{tabular}{|c|c|c|c|}
\hline \multirow[t]{2}{*}{ Pre-operative total knee replacement education delivery item ${ }^{a}$} & \multicolumn{3}{|c|}{$\%$ Important or Very Important rating } \\
\hline & Round $1(n=60)$ & Round $2(n=57)$ & Round $3(n=55)$ \\
\hline 2.1 Informed by a multidisciplinary team & 75 & 91 & 96 \\
\hline 2.2.1 Informed by members of the orthopaedic surgery team & 82 & 93 & 95 \\
\hline 2.2.2 Informed by members of the nursing team & 72 & 86 & 95 \\
\hline 2.2.3 Informed by members of the physiotherapy team & 95 & 98 & 100 \\
\hline 2.2.4 Informed by members of the occupational therapy team & 80 & 88 & 85 \\
\hline 2.2.5 Informed by members of the social work team & 42 & 42 & 31 \\
\hline 2.3 Informed by patients who have previously had TKR surgery & 63 & 67 & 73 \\
\hline 2.4 Provide examples of other patients' experiences of TKR surgery & 70 & 77 & 76 \\
\hline 2.5.1 Delivered using face-to-face group sessions & 78 & 89 & 89 \\
\hline 2.5.2 Delivered using face-to-face individual sessions & 45 & 56 & 56 \\
\hline 2.5.3 Delivered using a booklet or other written format & 88 & 98 & 100 \\
\hline 2.5.4 Delivered using a video or DVD & 63 & 65 & 64 \\
\hline 2.5.5 Delivered using a website or other electronic format & 72 & 74 & 75 \\
\hline 2.5.6 Delivered using telephone & 25 & 18 & 18 \\
\hline 2.5.7 Delivered using a PowerPoint presentation & 32 & 23 & 25 \\
\hline 2.6 Delivered using a combination of more than one format & 87 & 93 & 93 \\
\hline $\begin{array}{l}\text { 2.7 Delivered through a combination of information provision and } \\
\text { an opportunity to actively take part in tasks }\end{array}$ & 78 & 95 & 96 \\
\hline 2.8 Provide an opportunity for questions to be addressed & 97 & 100 & 100 \\
\hline 2.9 Provide an opportunity for a family member/friend to be involved & 80 & 91 & 93 \\
\hline 2.10 Tailored to each patient's needs & 85 & 82 & 91 \\
\hline 2.11 Tailored to the right or left knee & 13 & 7 & 2 \\
\hline 2.12 Received separately from patients waiting for other types of surgery & 67 & 75 & 76 \\
\hline 2.13 Delivered within 4 weeks of TKR surgery & N/A & 79 & 84 \\
\hline 2.14 Delivered in a hospital setting & N/A & 33 & 22 \\
\hline 2.15 Standardised across the UK & $\mathrm{N} / \mathrm{A}$ & 72 & 80 \\
\hline
\end{tabular}

N/A Not applicable because the item was not included in Round 1

TKR Total knee replacement

a Consensus was defined as at least 70\% of respondents rating an item as 'Important' or 'Very important'. Items in italics did not reach consensus in Round 3 and hence were excluded from the final list of recommendations. Items in bold were prioritised as 'Very important'. Items in plain text were prioritised as 'Important' Additional Files 2 and 7 provide the exact wording of each item

suggests some patients awaiting TKR believe 'A mechanical problem requires a mechanical fix', impairing their engagement with nonsurgical interventions [54]. This may partly explain some of the lower importance ratings amongst patient panellists compared to professional panellists.

The large number of education topics included in the final recommendations corresponds with qualitative literature highlighting the importance of comprehensive pre-operative TKR education [15, 17]. This study's findings also support and expand those of previous Delphi studies [29-33]. The most relevant previous study is that of Westby et al. (2018), a Canadian study that lists quality indicators on preoperative TKR education, exercise and weight management [29]. These largely align with the findings of the present study, although this study adds detail and there are disparities in the exercise types advocated. For example, pre-operative balance exercises are not specifically mentioned by Westby et al. (2018) [29], but were rated as 'Important' or 'Very important' by $100 \%$ of panellists in final round of this study (Item 3.6; Table 6). Additionally, pre-operative arm strengthening exercises are listed by Westby et al. (2018) [29], but were excluded from the present study's final recommendations (Item 3.2; Table 6). These disparities might be related to the differing methodology, expert panel composition and healthcare context of this study compared to the study of Westby et al. (2018) [29, 34, 42]. The disparities 
Table 6 Pre-operative total knee replacement exercise types: Importance ratings summary

\begin{tabular}{|c|c|c|c|}
\hline \multirow{2}{*}{$\begin{array}{l}\text { Pre-operative total knee replacement } \\
\text { exercise type item }^{\mathrm{a}}\end{array}$} & \multicolumn{3}{|c|}{$\%$ Important or Very Important rating } \\
\hline & Round $1(n=60)$ & Round $2(n=57)$ & Round $3(n=55)$ \\
\hline 3.1 Leg strengthening exercises & 98 & 100 & 100 \\
\hline 3.2 Arm strengthening exercises & 43 & 51 & 64 \\
\hline 3.3 Leg flexibility exercises & 83 & 95 & 98 \\
\hline 3.4 Arm flexibility exercises & 27 & 25 & 29 \\
\hline 3.5 Torso flexibility exercises & 43 & 32 & 27 \\
\hline 3.6 Balance exercises & 85 & 95 & 100 \\
\hline 3.7 Functional movement exercises & 87 & 96 & 95 \\
\hline 3.8 Functional technique exercises & 80 & 89 & 91 \\
\hline 3.9 Warm-up exercises & 58 & 60 & 55 \\
\hline 3.10 Cool-down exercises & 48 & 44 & 36 \\
\hline 3.11 Cardiovascular exercises & 60 & 67 & 75 \\
\hline 3.12 Core control exercises & 60 & 68 & 76 \\
\hline 3.13 Walking practice with walking aids & 83 & 88 & 91 \\
\hline 3.14 Training on steps & 83 & 91 & 95 \\
\hline 3.15 Practicing post-operative exercises & N/A & 89 & 96 \\
\hline 3.16 Water-based exercises & N/A & 32 & 25 \\
\hline 3.17 Exercises in which the foot does not move & N/A & 39 & 18 \\
\hline
\end{tabular}

N/A Not applicable because the item was not included in Round 1

${ }^{a}$ Consensus was defined as at least $70 \%$ of respondents rating an item as 'Important' or 'Very important'. Items in italics did not reach consensus in Round 3 and hence were excluded from the final list of recommendations. Items in bold were prioritised as 'Very important'. Items in plain text were prioritised as 'Important'

might also reflect uncertainties in the current preoperative TKR exercise evidence base [16].

\section{Strengths and limitations}

A key strength of this study is the rigorous application of a modified Delphi technique. Round 1 was developed from existing evidence to optimise the quality of the recommendations [41]. The web-based interface ensured that anonymity between panellists was maintained, which minimises social pressures and avoids group decisions being dominated by specific individuals [36]. Remote data collection facilitated inclusion of geographically dispersed panellists, with all four UK nations being represented (Tables 1-2). Another strength is the broad range of patients and professionals involved in the expert panel, with 87 and $97 \%$ of patient and professional panellists completing the final round respectively. This is likely to increase acceptance of the recommendations $[42,55]$.

This study also presents limitations. Notably, inclusion of all the items in the final recommendations was determined solely by expert consensus rather than empirical data. Therefore, the recommendations need to be interpreted and reviewed in light of emerging evidence. Free-text responses were only included in Round 1 and panellists were not asked to prioritise items, preventing an in-depth exploration of aspects such as the optimal exercise programme duration. Providing panellists with their individual responses from the preceding round may assist their decision-making [55], but this approach was not employed, primarily due to the restricted functionality of the Online surveys tool. All panellists were required to be able to use/access the Internet and email and the patient panellists were not necessarily fully representative of all patients undergoing TKR surgery (Table 1). In particular, $100 \%$ of the patient panellists identified as White British. Contributory factors to this may have included the requirement of panellists to be able to communicate in English and racial disparities in rates of TKR surgery [56].

\section{Implications for practice and future research}

Definitive evidence on pre-operative TKR education and prehabilitation is currently lacking $[16,18]$. Therefore, at present, the recommendations developed in this study provide a useful resource for helping to guide UK health professionals' decision-making on pre-operative TKR service provision. This could improve patient outcomes by reducing unwarranted variations between services and enhancing care quality. The large number of items included 
Table 7 Pre-operative total knee replacement exercise programme delivery: Importance ratings summary

\begin{tabular}{|c|c|c|c|}
\hline \multirow{2}{*}{$\begin{array}{l}\text { Pre-operative total knee replacement exercise delivery } \\
\text { item }^{\mathrm{a}}\end{array}$} & \multicolumn{3}{|c|}{$\%$ Important or Very Important rating } \\
\hline & Round $1(n=60)$ & Round $2(n=57)$ & Round $3(n=55)$ \\
\hline 4.1.1 Delivered using an individual instruction session & 52 & 53 & 44 \\
\hline 4.1.2 Delivered using supervised exercise sessions & 73 & 79 & 89 \\
\hline 4.1.3 Delivered using unsupervised exercise sessions & 58 & 72 & 91 \\
\hline 4.1.4 Delivered using telephone-delivered sessions & 5 & 9 & 5 \\
\hline 4.1.5 Delivered using a booklet or other written format & 87 & 93 & 93 \\
\hline 4.2 Delivered using a combination of more than one format & 87 & 96 & 91 \\
\hline 4.3.1 Take place in the patient's own home & 53 & 46 & 36 \\
\hline 4.3.2 Take place in a clinical setting & 52 & 47 & 47 \\
\hline 4.3.3 Take place in a community setting & 52 & 40 & 33 \\
\hline 4.4.1 Include high intensity exercises & 33 & 14 & 22 \\
\hline 4.4.2 Include low to moderate intensity exercises & 75 & 91 & 98 \\
\hline 4.5 Tailored to the patient's ability & 93 & 96 & 96 \\
\hline 4.6 Be progressive & 82 & 91 & 87 \\
\hline 4.7 Each session should last a minimum of $15 \mathrm{~min}$ & 63 & 63 & 80 \\
\hline 4.8 Involve a minimum of 2 sessions per week & 78 & 79 & 84 \\
\hline 4.9 Ideally be performed for a minimum of 6 weeks & 80 & 88 & 89 \\
\hline 4.10 Tailored to each patient's needs & N/A & 88 & 93 \\
\hline 4.11 Provide an opportunity for peer support & N/A & 65 & 75 \\
\hline 4.12 Include goal setting & $\mathrm{N} / \mathrm{A}$ & 79 & 87 \\
\hline
\end{tabular}

N/A Not applicable because the item was not included in Round 1

${ }^{a}$ Consensus was defined as at least $70 \%$ of respondents rating an item as 'Important' or 'Very important'. Items in italics did not reach consensus in Round 3 and hence were excluded from the final list of recommendations. Items in plain text were prioritised as 'Important'

Additional Files 2 and 7 provide the exact wording of each item

in the final recommendations may be off-putting to clinical decision-makers. The prioritised list of recommendations (Additional File 10) could however be used to select a limited number of recommendations that are relevant locally. The prioritised recommendations also provide a valuable resource for guiding future research on preoperative TKR interventions.
Arguably, the most challenging and costly recommendations to implement in clinical practice will be referral of patients with a BMI of $27 \mathrm{~kg} / \mathrm{m}^{2}$ or over to a weight management programme and referral of patients with anxiety or depression to CBT-based therapy if not already provided (Items 5.1, 5.2; Table 8). Neither of these recommendations are currently addressed in standard UK TKR

Table 8 Other pre-operative total knee replacement treatments: Importance ratings summary

\begin{tabular}{|c|c|c|c|}
\hline \multirow{2}{*}{$\begin{array}{l}\text { Other pre-operative total knee replacement treatment } \\
\text { item }^{\mathrm{a}}\end{array}$} & \multicolumn{3}{|c|}{$\%$ Important or Very Important rating } \\
\hline & Round $1(n=60)$ & Round $2(n=57)$ & Round $3(n=55)$ \\
\hline $\begin{array}{l}5.1 \text { Patients who have a BMl of } 27 \mathrm{~kg} / \mathrm{m}^{2} \text { or over should be } \\
\text { referred to a weight management programme }\end{array}$ & 67 & 67 & 73 \\
\hline $\begin{array}{l}\text { 5.2 Patients who have been formally diagnosed anxiety or } \\
\text { depression should be offered CBT-based therapy }\end{array}$ & 67 & 74 & 78 \\
\hline 5.3 Patients should be offered motivational interviewing & 38 & 37 & 33 \\
\hline 5.4 Patients should be offered neuromuscular electrical stimulation & 17 & 5 & 4 \\
\hline 5.5 Patients should be offered electro-acupuncture & 8 & 0 & 0 \\
\hline
\end{tabular}

\section{$B M I$ Body Mass Index}

CBT Cognitive behavioural therapy

${ }^{a}$ Consensus was defined as at least $70 \%$ of respondents rating an item as 'Important' or 'Very important'. Items in italics did not reach consensus in Round 3 and hence were excluded from the final list of recommendations. Items in plain text were prioritised as 'Important'

Additional File 2 provides the exact wording of each item 
pathways. Two panellists commented the BMI threshold of $27 \mathrm{~kg} / \mathrm{m}^{2}$ is quite low. Future research investigating whether specific subgroups of patients benefit from preoperative TKR weight management and psychological support is therefore warranted.

Use of the recommendations is likely to be affected by the COVID-19 pandemic. The recommended education and exercise delivery approaches need to be interpreted with consideration of the new impetus for remote models of care [28, 57]. Digital interventions offer a particularly valuable approach for delivering TKR care remotely at relatively low cost [58-60], making this an important area for future research. The present study's authors intend to help address this by using the final set of recommendations to inform a future pre-operative TKR education and prehabilitation digital intervention. The COVID-19 pandemic is also substantially increasing the length of time patients remain on the waiting list for TKR surgery [26]. Correspondingly, another key consideration is how to support patients to engage with a preoperative TKR exercise programme for a prolonged period. Research addressing this, and the disparities regarding pre-operative TKR exercise types noted above, would therefore be valuable.

\section{Conclusions}

This UK-based modified Delphi study developed a comprehensive set of recommendations on pre-operative TKR education and prehabilitation. These cover 34 education topics, 18 education delivery approaches, 10 exercise types, 13 exercise delivery approaches and two other pre-operative treatments. Due to the absence of definitive evidence in this area, inclusion of items in the final recommendations was based solely on expert consensus. Therefore, these recommendations will need to be interpreted and reviewed as necessary in light of new evidence. Until such evidence emerges, the recommendations provide a useful resource for helping to guide health professionals' decision-making on pre-operative TKR service provision.

\section{Abbreviations}

BMl: Body mass index; CBT: Cognitive behavioural therapy; NHS: National health service; TKR: Total knee replacement; UK: United Kingdom

\section{Supplementary Information}

The online version contains supplementary material available at https:/doi. org/10.1186/s12891-021-04160-5.

Additional file 1: Sampling strategy. Sampling strategy used to select panellists for inclusion in the study (Supplementary Table 1).

Additional file 2. Round 1 survey. Round 1 survey administered during the study.
Additional file 3: Formative categorisation matrix. Formative categorisation matrix developed from the Round 1 survey (Supplementary Table 2).

Additional file 4: Recruitment flow charts. Patient recruitment flow chart (Supplementary Fig. 1) and professional recruitment flow chart (Supplementary Fig. 2).

Additional file 5: Final categorisation matrix. Final categorisation matrix developed from the content analysis of the Round 1 free-text responses (Supplementary Table 3).

Additional file 6: Inductively generated main category. Inductively generated main category developed during the content analysis of panellists' Round 1 free-text responses (Supplementary Table 4).

Additional file 7: Round 2 new items. New items generated from panellists' Round 1 free-text responses and included in the Round 2 survey (Supplementary Table 5).

Additional file 8. Final list of recommendations. Final list of recommendations developed from the Round 3 results.

Additional file 9: Detailed importance ratings results. Detailed importance rating results for Round 1 (Supplementary Tables 6-10), Round 2 (Supplementary Tables 11-15) and Round 3

(Supplementary Tables 16-20).

Additional file 10: Prioritised list of recommendations. Prioritised list of recommendations developed from the Round 3 results (Supplementary Tables 21-25)

\section{Acknowledgements}

The authors would like to thank: all the individuals who participated in the study; the patient representatives and professionals who helped develop the study materials and pilot test the online surveys; the Project Advisory Group members for their oversight of the study; and the following organisations/ groups for their assistance with the study recruitment:

- Association of Trauma and Orthopaedic Chartered Physiotherapists

- Arthroplasty Care Practitioner's Association

- Royal College of Nursing Society of Orthopaedics and Trauma Nursing

- Royal College of Occupational Therapists Specialist Section - Trauma and Orthopaedics

- UK Total Knee Replacement and Recovery UK Facebook group

- MSK: Public Health \& Prevention Facebook group

Authors' contributions

AMA: study conception, study design, data acquisition, data analysis, data interpretation and drafting the manuscript. CC: study conception, study design and data analysis. TOS: study design. BTD: study conception and study design. HP: data interpretation. DA: study design. ACR: study conception and study design. GAM: study design and data analysis. All authors contributed to revising the manuscript. The author(s) read and approved the final manuscript.

\section{Funding}

This paper presents independent research supported by the National Institute for Health Research (NIHR) Leeds Biomedical Research Centre (BRC). Professor Redmond and Professor Pandit are National Institute for Health Research (NIHR) Senior Investigators. Anna Anderson, Clinical Doctoral Research Fellow, ICA-CDRF-2018-04-ST2-006, is funded by Health Education England (HEE) / National Institute for Health Research (NIHR) for this research project. The views expressed in this publication are those of the author(s) and not necessarily those of the NIHR, NHS or the UK Department of Health and Social Care. The funding body had no role in the study design, collection analysis and interpretation of data or writing the manuscript.

Availability of data and materials

The datasets used and/or analysed during the current study are available from the corresponding author on reasonable request. 


\section{Declarations}

\section{Ethics approval and consent to participate}

This study was approved by the London - Riverside Research Ethics Committee, United Kingdom (Reference number: 19/LO/0813). All panellists provided electronic informed consent by completing a Consent Statement included on the introductory page of all surveys administered during the study.

\section{Consent for publication}

Not applicable

\section{Competing interests}

The authors declare that they have no competing interests.

\begin{abstract}
Author details
'Leeds Institute of Rheumatic \& Musculoskeletal Medicine, University of Leeds, Leeds, UK. ${ }^{2} \mathrm{NIHR}$ Leeds Biomedical Research Centre, Leeds, UK. ${ }^{3}$ Leeds Community Healthcare NHS Trust Musculoskeletal and Rehabilitation Services, Leeds, UK. ${ }^{4}$ School of Health Sciences, University of East Anglia, Norwich, UK. ${ }^{5}$ Nuffield Department of Orthopaedics, Rheumatology and Musculoskeletal Sciences, University of Oxford, Oxford, UK. ${ }^{6}$ School of Healthcare, University of Leeds, Leeds, UK. PPysiotherapy Department, Bury Care Organisation, Northern Care Alliance NHS Group, Bury, England, UK.
\end{abstract}

\section{Received: 19 August 2020 Accepted: 9 March 2021}

\section{Published online: 14 April 2021}

\section{References}

1. Culliford D, Maskell J, Judge A, Cooper C, Prieto-Alhambra D, Arden NK. Future projections of total hip and knee arthroplasty in the UK: results from the UK clinical practice research Datalink. Osteoarthr Cartil. 2015;23(4):594600. https://doi.org/10.1016/j.joca.2014.12.022.

2. Ackerman IN, Bohensky MA, Zomer E, Tacey M, Gorelik A, Brand CA, et al. The projected burden of primary total knee and hip replacement for osteoarthritis in Australia to the year 2030. BMC Musculoskelet Disord. 2019;20(1):90.

3. National Services Scotland Information and Intelligence. Scottish Arthroplasty Project Report 2019. Activity - Type of Arthroplasty 2019. https://www.arthro.scot.nhs.uk/Reports/Visualisation.html. Accessed 27 Aug 2019.

4. The NJR Editorial Board. 16th annual report 2019: National Joint Registry for England. Wales: Northern Ireland and the Isle of Man; 2019. https://reports. njrcentre.org.uk/. Accessed 7 Jul 2020

5. Desmeules F, Dionne CE, Belzile E, Bourbonnais R, Frémont P. The burden of wait for knee replacement surgery: effects on pain, function and healthrelated quality of life at the time of surgery. Rheumatology (Oxford). 2010; 49(5):945-54. https://doi.org/10.1093/rheumatology/kep469.

6. McHugh GA, Luker KA, Campbell M, Kay PR, Silman AJ. Pain, physical functioning and quality of life of individuals awaiting total joint replacement: a longitudinal study. J Eval Clin Pract. 2008;14(1):19-26. https:// doi.org/10.1111/j.1365-2753.2007.00777.x.

7. Jones AR, Al-Naseer S, Bodger O, James ETR, Davies AP. Does pre-operative anxiety and/or depression affect patient outcome after primary knee replacement arthroplasty? Knee. 2018;25(6):1238-46. https://doi.org/10.1016/ j.knee.2018.07.011.

8. Hamilton DF, Lane JV, Gaston P, Patton JT, Macdonald D, Simpson AH, et al. What determines patient satisfaction with surgery? A prospective cohort study of 4709 patients following total joint replacement. BMJ Open. 2013; 3(4):e002525. https://doi.org/10.1136/bmjopen-2012-002525.

9. Baker PN, van der Meulen JH, Lewsey J, Gregg PJ. The role of pain and function in determining patient satisfaction after total knee replacement. Data from the National Joint Registry for England and Wales. J Bone Joint Surg Br. 2007;89(7):893-900.

10. Conner-Spady BL, Bohm E, Loucks L, Dunbar MJ, Marshall DA, Noseworthy TW. Patient expectations and satisfaction 6 and 12 months following total hip and knee replacement. Qual Life Res. 2020;29(3):705-19. https://doi. org/10.1007/s11136-019-02359-7.

11. Wood TJ, Petruccelli DT, Tushinski DM, Winemaker MJ, de Beer J. Nuisance symptoms in Total joint Arthroplasty: prevalence and impact on patient satisfaction. J Arthroplast. 2020;35(3):661-70. https://doi.org/10.1016/j.arth.2 019.10.034.
12. Nam D, Berend ME, Nunley RM, Della Valle CJ, Berend KR, Lombardi AV, Barrack RL. Residual symptoms and function after Unicompartmental and Total knee Arthroplasty: comparable to normative controls? J Arthroplast. 2016:31(10):2161-6. https://doi.org/10.1016/j.arth.2016.02.064.

13. Parvizi J, Nunley RM, Berend KR, Lombardi AV Jr, Ruh EL, Clohisy JC, et al. High level of residual symptoms in young patients after total knee arthroplasty. Clin Orthop Relat Res. 2014;472(1):133-7. https://doi.org/10.1 007/s11999-013-3229-7.

14. Edwards PK, Mears SC, Lowry BC. Preoperative education for hip and knee replacement: never stop learning. Curr Rev Musculoskelet Med. 2017;10(3): 356-64. https://doi.org/10.1007/s12178-017-9417-4.

15. Goldsmith LJ, Suryaprakash N, Randall E, Shum J, MacDonald V, Sawatzky R, Hejazi S, Davis JC, McAllister P, Bryan S. The importance of informational, clinical and personal support in patient experience with total knee replacement: a qualitative investigation. BMC Musculoskelet Disord. 2017; 18(1):127. https://doi.org/10.1186/s12891-017-1474-8.

16. Moyer R, lkert K, Long K, Marsh J. The value of preoperative exercise and education for patients undergoing Total hip and knee Arthroplasty: a systematic review and meta-analysis. JBJS Rev. 2017;5(12):e2. https://doi. org/10.2106/JBJS.RWW.17.00015.

17. Buus AAØ, Hejlsen OK, Dorisdatter Bjørnes C, Laugesen B. Experiences of pre- and postoperative information among patients undergoing knee arthroplasty: a systematic review and narrative synthesis. Disabil Rehabil. 2019;43(2):150-62. https://doi.org/10.1080/09638288.2019.1615997.

18. McDonald S, Page MJ, Beringer K, Wasiak J, Sprowson A. Preoperative education for hip or knee replacement. Cochrane Database Syst Rev. 2014; 13(5):CD003526

19. Chen H, Li S, Ruan T, Liu L, Fang L. Is it necessary to perform prehabilitation exercise for patients undergoing total knee arthroplasty: meta-analysis of randomized controlled trials. Phys Sportsmed. 2018;46(1):36-43. https://doi. org/10.1080/00913847.2018.1403274.

20. Durrand J, Singh SJ, Danjoux G. Prehabilitation. Clin Med (Lond). 2019;19(6): 458-64. https://doi.org/10.7861/clinmed.2019-0257.

21. Banugo P, Amoako D. Prehabilitation. BJA Education. 2017;17(12):401-5. https://doi.org/10.1093/bjaed/mkx032.

22. National Institute for Health and Care Excellence. Joint replacement (primary): hip, knee and shoulder (NICE guideline [NG157]). 2020. https:// www.nice.org.uk/guidance/ng157. Accessed 7 Jul 2020.

23. Drew S, Judge A, Cohen R, Fitzpatrick R, Barker K, Gooberman-Hill R. Enhanced recovery after surgery implementation in practice: an ethnographic study of services for hip and knee replacement. BMJ Open. 2019:9(3):e024431. https://doi.org/10.1136/bmjopen-2018-024431.

24. Getting It Right first time. Getting It Right in Orthopaedics: Reflecting on success and reinforcing improvement 2020. https://gettingitrightfirsttime.co. uk/wp-content/uploads/2020/02/GIRFT-orthopaedics-follow-up-reportFebruary-2020.pdf. Accessed 7 Jul 2020.

25. Versus Arthritis. Thousands facing an agonising wait for joint replacement surgery. 2020. https://www.versusarthritis.org/news/2020/february/thousands-fa cing-an-agonising-wait-for-joint-replacement-surgery/. Accessed 7 Jul 2020

26. British Orthopaedic Association. A message for people waiting for joint replacement and other orthopaedic surgery. 2020. https://www.boa.ac.uk/ resources/a-message-for-people-waiting-for-joint-replacement-and-otherorthopaedic-surgery.html. Accessed 7 Jul 2020.

27. Gilbert AW, Billany JCT, Adam R, Martin L, Tobin R, Bagdai S, Galvin N, Farr I, Allain A, Davies L, Bateson J. Rapid implementation of virtual clinics due to COVID-19: report and early evaluation of a quality improvement initiative. BMJ Open Qual. 2020;9(2):e000985. https://doi.org/10.1136/bmjoq-2020-000985.

28. Fisk M, Livingstone A, Pit SW. Telehealth in the context of COVID-19: changing perspectives in Australia, the United Kingdom, and the United States. J Med Internet Res. 2020;22(6):e19264. https://doi.org/10.2196/19264.

29. Westby MD, Marshall DA, Jones CA. Development of quality indicators for hip and knee arthroplasty rehabilitation. Osteoarthr Cartil. 2018;26(3):370-82. https://doi.org/10.1016/j.joca.2017.10.020.

30. Plenge $U$, Nortje MB, Marais LC, Jordaan JD, Parker $R$, van der Westhuizen $N$, et al. Optimising perioperative care for hip and knee arthroplasty in South Africa: a Delphi consensus study. BMC Musculoskelet Disord. 2018;19(1):140.

31. Ruiz Iban MA, Tejedor A, Gil Garay E, Revenga C, Hermosa JC, Montfort J, Peña MJ, López Millán JM, Montero Matamala A, Capa Grasa A, Navarro MJ, Gobbo M, Loza E. GEDOS-SECOT consensus on the care process of patients with knee osteoarthritis and arthoplasty. Rev Esp Cir Ortop Traumatol. 2017; 61(5):296-312. https://doi.org/10.1016/j.recot.2017.03.006. 
32. SooHoo NF, Lieberman JR, Farng E, Park S, Jain S, Ko CY. Development of quality of care indicators for patients undergoing total hip or total knee replacement. BMJ Qual Saf. 2011;20(2):153-7. https://doi.org/10.1136/ bmjgs.2009.032524.

33. Ruiz Ibán MA, Maculé F, Torner P, Gil Garay E, Oteo-Álvaro A, López Millán $J M$, et al. SECOT-GEDOS consensus on pre-surgical pain management in knee and hip arthrosis. Rev Esp Cir Ortop Traumatol. 2015;59(3):186-99.

34. Marshall MN, Shekelle PG, McGlynn EA, Campbell S, Brook RH, Roland MO Can health care quality indicators be transferred between countries? Qual Saf Health Care. 2003;12(1):8-12. https://doi.org/10.1136/qhc.12.1.8.

35. Armstrong MJ, Rueda JD, Gronseth GS, Mullins CD. Framework for enhancing clinical practice guidelines through continuous patient engagement. Health Expect. 2017;20(1):3-10. https://doi.org/10.1111/ hex.12467.

36. Jünger S, Payne SA, Brine J, Radbruch L, Brearley SG. Guidance on conducting and REporting DElphi studies (CREDES) in palliative care: recommendations based on a methodological systematic review. Palliat Med. 2017;31(8):684-706. https://doi.org/10.1177/0269216317690685.

37. Diamond IR, Grant RC, Feldman BM, Pencharz PB, Ling SC, Moore AM, Wales PW. Defining consensus: a systematic review recommends methodologic criteria for reporting of Delphi studies. J Clin Epidemiol. 2014;67(4):401-9. https://doi.org/10.1016/j.jclinepi.2013.12.002.

38. Keeney S, Hasson F, McKenna H. The Delphi technique in nursing and Health Research. 1st ed. Chichester, United Kingdom: Wiley-Blackwell; 2011 https://doi.org/10.1002/9781444392029.

39. Rowe $G$, Wright $G$, Bolger F. Delphi: a reevaluation of research and theory. Technol Forecast Soc Change. 1991;39(3):235-51. https://doi.org/10.1016/ 0040-1625(91)90039-I.

40. Veugelers R, Gaakeer MI, Patka P, Huijsman R. Improving design choices in Delphi studies in medicine: the case of an exemplary physician multi-round panel study with 100\% response. BMC Med Res Methodol. 2020;20(1):156. https://doi.org/10.1186/s12874-020-01029-4

41. Cruse H, Winiarek M, Marshburn J, Clark O, Djulbegovic B. Quality and methods of developing practice guidelines. BMC Health Serv Res. 2002;2(1). https://doi.org/10.1186/1472-6963-2-1.

42. Murphy MK, Black NA, Lamping DL, McKee CM, Sanderson CF, Askham J, et al. Consensus development methods, and their use in clinical guideline development. Health Technol Assessment. 1998;2(3):1-88.

43. Daniel J. Choosing the type of nonprobability sampling. In: sampling essentials: practical guidelines for making sampling choices [internet]. Thousand Oaks, CA: SAGE Publications, Inc.; 2012. https://methods.sagepub. com/book/sampling-essentials. Accessed 4 Aug 2020. https://doi.org/10.413 5/9781452272047.

44. Guest G, Namey E, Mitchell M. Sampling in Qualitative Research. In: Collecting qualitative data. London: SAGE Publications, Ltd; 2013. p. 41-74.

45. Sadler GR, Lee H-C, Lim RS-H, Fullerton J. Recruitment of hard-to-reach population subgroups via adaptations of the snowball sampling strategy. Nurs Health Sci. 2010;12(3):369-74. https://doi.org/10.1111/ j.1442-2018.2010.00541.x

46. Trevelyan EG, Robinson PN. Delphi methodology in health research: how to do it? Eur J Integr Med. 2015;7(4):423-8. https://doi.org/10.1016/ j.eujim.2015.07.002.

47. Jisc. Online surveys. 2019. https://www.onlinesurveys.ac.uk/. Accessed 7 Sept 2019.

48. Hsu C-C, Sandford BA. The delphi technique: making sense of consensus. Pract Assessment Res Eval. 2007;12(10).

49. Hsieh HF, Shannon SE. Three approaches to qualitative content analysis. Qual Health Res. 2005;15(9):1277-88. https://doi.org/10.1177/10497323 05276687.

50. Assarroudi A, Heshmati Nabavi F, Armat MR, Ebadi A, Vaismoradi M. Directed qualitative content analysis: the description and elaboration of its underpinning methods and data analysis process. J Res Nurs. 2018;23(1):4255. https://doi.org/10.1177/1744987117741667

51. French SD, Bennell KL, Nicolson PJ, Hodges PW, Dobson FL, Hinman RS. What do people with knee or hip osteoarthritis need to know? An international consensus list of essential statements for osteoarthritis. Arthritis Care Res (Hoboken). 2015;67(6):809-16. https://doi.org/10.1002/acr.22518.

52. Robinson KR, Leighton $P$, Logan $P$, Gordon AL, Anthony $K$, Harwood RH, Gladman JRF, Masud T. Developing the principles of chair based exercise for older people: a modified Delphi study. BMC Geriatr. 2014;14(1):65. https:// doi.org/10.1186/1471-2318-14-65.
53. Wells C, Kolt GS, Marshall P, Bialocerkowski A. The definition and application of Pilates exercise to treat people with chronic low back pain: a Delphi survey of Australian physical therapists. Phys Ther. 2014;94(6):792-805. https://doi.org/10.2522/ptj.20130030.

54. Bunzli S, O'Brien P, Ayton D, Dowsey M, Gunn J, Choong P, et al. Misconceptions and the acceptance of evidence-based nonsurgical interventions for knee osteoarthritis. A qualitative study. Clin Orthop Relat Res. 2019;477(9):1975-83. https://doi.org/10.1097/CORR.0000000000000784.

55. Boulkedid R, Abdoul H, Loustau M, Sibony O, Alberti C. Using and reporting the Delphi method for selecting healthcare quality indicators: a systematic review. PLoS One. 2011;6(6):e20476. https://doi.org/10.1371/journal.pone.0020476.

56. Smith MC, Ben-Shlomo Y, Dieppe P, Beswick AD, Adebajo AO, Wilkinson JM, Blom AW, National Joint Registry for England, Wales and Northern Ireland. Rates of hip and knee joint replacement amongst different ethnic groups in England: an analysis of National Joint Registry data. Osteoarthr Cartil. 2017; 25(4):448-54. https://doi.org/10.1016/j.joca.2016.12.030.

57. Greenhalgh T, Wherton J, Shaw S, Morrison C. Video consultations for covid19. BMJ. 2020;368:m998.

58. Zachwieja E, Theosmy EG, Yacovelli SJ, Beatty EW, McGrath ME, Lonner JH. Web-based self-directed exercise program is cost-effective compared to formal physical therapy after primary Total knee Arthroplasty. J Arthroplast. 2020:35(9):2335-41. https://doi.org/10.1016/j.arth.2020.04.061.

59. Timmers $T$, Janssen $L$, van der Weegen W, Das D, Marijnissen WJ, Hannink G, van der Zwaard BC, Plat A, Thomassen B, Swen JW, Kool RB, Lambers Heerspink FO. The effect of an app for day-to-day postoperative care education on patients with Total knee replacement: randomized controlled trial. JMIR Mhealth Uhealth. 2019;7(10):e15323. https://doi.org/10.2196/15323.

60. Jayakumar P, Di J, Fu J, Craig J, Joughin V, Nadarajah V, et al. A patientfocused technology-enabled program improves outcomes in primary Total hip and knee replacement surgery. JB JS Open Access. 2017;2(3):e0023. https://doi.org/10.2106/JBJS.OA.16.00023.

\section{Publisher's Note}

Springer Nature remains neutral with regard to jurisdictional claims in published maps and institutional affiliations.

Ready to submit your research? Choose BMC and benefit from:

- fast, convenient online submission

- thorough peer review by experienced researchers in your field

- rapid publication on acceptance

- support for research data, including large and complex data types

- gold Open Access which fosters wider collaboration and increased citations

- maximum visibility for your research: over $100 \mathrm{M}$ website views per year

At $\mathrm{BMC}$, research is always in progress.

Learn more biomedcentral.com/submissions 